\title{
Engel on Doxastic Correctness
}

\author{
Conor McHugh
}

This is the accepted manuscript. The final publication is available on the journal's website: http://link.springer.com/article/10.1007/s11229-015-0767-4

\begin{abstract}
In this paper I discuss Pascal Engel's recent work on doxastic correctness. I raise worries about two elements of his view - the role played in it by the distinction between $i$ correctness and $e$-correctness, and the construal of doxastic correctness as an ideal of reason. I propose an alternative approach.
\end{abstract}

It is a great privilege to contribute to this festschrift for Pascal Engel, and thereby pay a small tribute to his important, wide-ranging contributions to Philosophy in recent decades. I also offer this piece as a token of gratitude. As well as lively, stimulating, and, on Pascal's side, erudite philosophical discussion, Pascal has also offered me much generous personal and professional support over the years. In addition, I think that all philosophers in the so-called analytic tradition, and all who endorse the values of clarity, humility and open-mindedness that, at its best, this tradition represents, owe Pascal thanks for his tireless efforts in its defence.

My topic here is one on which much of Pascal's recent work has focused: belief and its norms. In particular, I want to discuss how we should best characterise doxastic correctness.

\section{Doxastic Correctness}

It is a platitude that beliefs can be correct or incorrect. And it is very widely held that the standard of correctness for belief is truth: that is, that beliefs are correct just when true. ${ }^{1}$ But what do these claims amount to? Pascal Engel, like many others, holds that doxastic correctness is normative (Engel 2013a, 2013b). On this view, to say that true beliefs are correct is to say that true beliefs satisfy some norm;

\footnotetext{
${ }^{1}$ But see Engel (2004), Smithies (2012).
} 
to say that false beliefs are incorrect is to say that they violate this norm. It's not hard to see why this is a natural view. When we say that someone has an incorrect belief, we do not seem to be merely describing some feature of her, or of her belief--a feature whose presence she could sensibly remain unconcerned by. We are saying that she believes wrongly. This looks normative.

It is also natural to think that this normative standard of doxastic correctness not only applies necessarily, but is essential to the attitude of belief. An attitude not assessable as correct or incorrect according to the truth or falsity of its content would thereby fail to count as a belief.

I am sympathetic both to the claim that doxastic correctness is normative, and to the claim that being subject to this standard is essential to belief. Here I will focus primarily on the first claim. I do not want to question the truth of the claim, but rather to ask about the normative property that is involved here. What kind of property is it? A deontic property - a property in the same family as obligation and permission? Or an evaluative one, like goodness and badness? Or something else?

These are questions with respect to which Pascal Engel has done much to advance our understanding. Here I will focus on the view that he expounds in his recent article, 'Doxastic Correctness' (Engel 2013b). I will raise worries about two elements of that view - the role played in it by the distinction between $i$-correctness and $e$-correctness, and the construal of doxastic correctness as an ideal of reason. I will propose an alternative construal of doxastic correctness, that requires rejecting Engel's claims about $i$-correctness and $e$-correctness.

\section{I-Correctness and $E$-Correctness}

Following Thomson (2008, Ch. VI), Engel distinguishes between 'internal' correctness and 'external' correctness, or $i$-correctness and $e$-correctness. Consider the act of asserting some proposition. This act can be performed correctly in the sense that one utters a grammatical sentence that expresses that proposition, one pronounces all the words in the right way, one speaks sufficiently loudly, and so on. In that case, one's act of assertion is $i$-correct. We can also say that one has made a correct assertion in the sense that what one has asserted is true. In that case, one's assertion is $e$-correct. Clearly, these two ways of being correct can come apart. One can perform in an exemplary way the act of asserting a proposition that is in fact false, and one can do a very bad job of asserting a proposition that is true. 
The truth-standard of doxastic correctness seems to correspond to $e$-correctness. But this, for Engel, raises a worry about whether doxastic correctness is really normative. He writes:

is it clear that $[e-]$ correctness is a normative property? The standard for a tune is fixed by a set of notes, the standard for a map is fixed by the similarity between the map and the territory represented, the correct spelling is fixed by a certain pronunciation of the word. These are descriptive properties, not normative ones. ... The normative concept of correctness is distinct from this descriptive one. It concerns the way, or the operation which, an agent has to perform in order to meet the descriptive condition (Engel 2013b, 200).

The worry here seems to be that $e$-correctness for various kinds requires merely the possession of a certain descriptive (i.e. non-normative) property, such as containing certain notes in a certain order. Note that this seems to be true in particular for the kind belief, since truth appears to be a purely descriptive property. ${ }^{2}$ On the other hand, $i$-correctness seems to be a matter of doing what one does more or less well--something that does look normative.

On the basis of this and other considerations, Engel concludes that

for a kind $K$ to be correct it has to meet both the $e$ - and the $i$-correctness conditions. It would be wrong to reduce correctness to either one of these two dimensions (ibid., 201).

The suggestion, then, seems to be that correctness, and doxastic correctness in particular, comprises both $e$-and $i$-correctness, and that it is only because it includes $i$-correctness that it is normative.

It's worth noting that this isn't exactly Thomson's view of things. She does not talk of some overarching correctness property consisting of the conjunction of $e$-correctness and $i$-correctness. Rather, she simply holds that $e$-correctness and $i$-correctness are distinct normative properties. Indeed,

\footnotetext{
${ }^{2}$ More precisely, the relevant property for belief is that of having a true propositional content. It's not uncontroversial that this is descriptive. Both content and truth are famously held by some philosophers to be normative.
} 
we might want to say that $e$-correctness and $i$-correctness merely correspond to distinct kinds of standard of correctness to which certain things, such as assertions, can be held--an external standard and an internal standard--rather than being different kinds of property. In that case it would be hard to see how one of them could be a normative property and the other not.

Of course, one could use 'correctness' in a stipulative way to refer to the property that consists in being both $e$-correct and $i$-correct. But the question would remain whether this property has any theoretical interest.

One worry about Engel's proposal is that it might entail that no beliefs are correct, since, on the face of it, the notion of $i$-correctness does not obviously apply to belief at all. Pauline can assert that $p$ better than Pierre asserts it - because of her superior grammar or diction, say. But, as Thomson points out, it would be odd to talk of one person believing that $p$ better than another person. Pauline might believe that $p$ more strongly than Pierre does, or with more certainty than him. She might understand better what is involved in its being the case that $p$. But none of this seems to amount to believing better; believing as such doesn't seem to be the sort of thing one can do a better or worse job of. After all, as Engel says, believing is "not a performance" (ibid.). This suggests that, in so far as the distinction between $e$-correctness and $i$-correctness is in good standing, doxastic correctness is just a species of $e$-correctness (or, as we might better say, correctness with an $e$-standard).

In response to this sort of worry, Engel suggests that we understand $i$-correctness for belief as follows:

\footnotetext{
"Believing for bad reasons, or on the basis of insufficient evidence, is poor believing and thus $i$-incorrect" (ibid.).
}

Thus, doxastic $i$-correctness is a matter of basing one's beliefs on appropriate grounds. This ingenious idea takes advantage of the point that, while believing per se is not something one can do more or less well, basing one's beliefs arguably is.

Nonetheless, I am sceptical that this is really a kind of doxastic correctness. Or, at any rate, I am sceptical that this property, together with doxastic e-correctness, forms part of an interesting, overarching correctness property possessed by beliefs. This is for several reasons. 
First, the appropriateness of the way in which a belief is based is, as Engel acknowledges, in the first instance a property not of the belief itself but of some broader state or activity that includes it. It seems that what we have here is, at best, two things that can be assessed as correct or incorrect, rather than one thing that can be assessed as correct or incorrect along two different dimensions, in such a way that it might be thought of as 'fully correct' when correct along both dimensions. This is not to say that the appropriateness of the way in which a belief is based is not a property of the belief at all. It is a relational property of the belief (e-correctness is also relational, of course, but it is not in the same way a property of something else in the first instance). Nor is it to say that we can't consider whether a belief possesses the conjunctive property of being $e$-correct and being appropriately based. It is to question whether this conjunctive property is itself a further correctness property possessed by the belief, instead of being a conjunction of two rather different properties. Consider a belief that is appropriately based but turns out to be false. We would not say that this belief is partly, but not fully, correct. We would simply say that it is incorrect, though appropriately based.

Second, it seems odd to think of appropriate basing as a form of correctness at all. Perhaps we can talk about correct and incorrect reasoning - though I think it's more accurate to talk about good and bad reasoning - but it doesn't seem natural to talk about the basing relation that comes to be instantiated through such reasoning as itself correct or incorrect. It seems to me closer to properties like rationality, reasonability, justification, and the like. It might be argued that these terms are synonymous with a certain sense of 'correctness'. I doubt this, but even if so, the previous point suggests that this is not a sense of 'correctness' that applies to the belief itself. It is very plausible that a belief can be correct but, say, unreasonable, or vice versa.

Third, it is natural to think that what counts as appropriate doxastic basing depends in part on the standard of correctness for belief: it is appropriate to base one's beliefs on evidence precisely because evidence is connected to truth, and true beliefs are $\left(e\right.$-) correct. ${ }^{3}$ If that's right, then the truth-standard of doxastic correctness is more fundamental than the standard for appropriate basing of beliefs. It would be odd, then, to think that the truth-standard, and the standard for appropriate basing, somehow

\footnotetext{
${ }^{3}$ That epistemic norms of appropriate basing and the like are derived from the fundamental standard of true belief is a very widely held, though often implicit, assumption. For examples of its being made explicit see e.g. Bonjour (1985), Wedgwood (2002), Alston (2005), Sosa (2007).
} 
come together to form a further, conjunctive property of correctness. Perhaps they do form an interesting conjunctive property, but this would seem to be a different kind of property that incorporates correctness, rather than a further correctness property.

I am suggesting that the notion of $i$-correctness does not apply to belief. That leaves $e$-correctness. But, as we saw, being $e$-correct often seems to be simply a matter of possessing some descriptive property - whatever property is fixed as the standard of $e$-correctness for the relevant kind. In the doxastic case it is truth. Are we therefore forced to concede that doxastic correctness is not normative after all?

I don't think we should concede so easily that $e$-correctness is not normative. We must distinguish between the standard of correctness for a given kind - the property in virtue of which something counts as correct of that kind - and the property of correctness itself (having argued that the notion of $i$-correctness has no role in this context, henceforth I will drop the ' $e$ ' prefix). It would be a mistake to think that we give an account of doxastic correctness simply by citing the standard of correctness for belief. Truth is the property a given belief must have in order to have the further property of being correct. Citing it doesn't tell you the nature of the further property of correctness that the belief thereby has. To see this, note that this is an instance of a property that other attitudes can also have. For example, you can correctly intend a certain course of action. It's correct to intend to phone your sister on her birthday, and incorrect to intend to murder everyone you know. The standard for correct intention is not truth. It is tied instead to the choiceworthiness of available courses of action (as well as, perhaps, the likelihood of successful execution). It doesn't matter for our purposes what exactly it takes for intended action to be choiceworthy. What matters is that correctness is a property in common between correct beliefs and correct intentions, and is therefore not identical to truth. Rather, truth is what makes beliefs correct. Some other property makes intentions correct. This point can be obscured by formulations to the effect that correctness for belief is, or consists in, truth.

Once we distinguish between the standard of correctness for a given kind and the property of correctness itself, there is room to suppose that the standard of correctness is non-normative, but that correctness itself is normative. That is, it may be that the standard of correctness for a certain kind can be specified in wholly non-normative terms--for example, the standard might be having a true 
propositional content--but satisfying that standard gives a thing of that kind the normative property of being correct.

In general, it is not obviously problematic to say that something's having a non-normative property gives it a distinct normative property. In ethics, utilitarians may say that what makes an action right is that it maximises pleasure. This is a non-normative property. Utilitarians need not claim that rightness itself is therefore non-normative. They can say that pleasure-maximisation makes actions right, but deny that the property of rightness is identical to the non-normative property of pleasuremaximisation. Defenders of other ethical theories, like Kantianism and contractualism, can make similar moves. Perhaps none of these views is sustainable, but they are not obviously confused from the start. $^{4}$

But, it might be asked, why should being true give beliefs a normative property? Granted, true beliefs tend to have certain benefits--for example, they help us to get what we want--but it is largely a contingent matter whether any particular true belief will lead to such benefits. So one might wonder what the big deal is about true belief. ${ }^{5}$ It is at this point that it becomes attractive to think that the nature of belief does some work in explaining the norms governing belief. For it seems that the attitude of belief is, in a certain way, made for truth. When what you believe is true you thereby believe rightly, whether or not this brings any benefits.

However, even leaving aside the question of how exactly these norms are explained, it might be objected that my suggestion here ignores the lesson of Engel's other examples of $(e-)$ correctness: the correctness of a performance of a tune, a map, or a spelling of a word. Suppose you misspell a word. Have you done something wrong? Well, you have spelled the word wrongly. But it's not clear that this alone is a normative matter in anything other than a deflated sense. After all, you may not have been aiming to spell the word correctly, and may have had no reasons to do so. In that case, it doesn't seem as though you should necessarily care that you spelled it incorrectly. Doesn't this show that correctness per se is not normative? ${ }^{6}$

\footnotetext{
${ }^{4}$ Compare Parfit (2011, pp. 368ff.) on what makes actions wrong.

${ }_{6}^{5}$ See, e.g., Papineau (2013), for these sorts of worries.

${ }^{6}$ Compare Rosen (2001), Hattiangadi (2007).
} 
It may show that the term 'correctness' need not always be used to pick out a normative property. But it does not show that uses of 'correct' never pick out a property that is normative. To this point I have been talking about correctness as though this is simply a property in common to all things that can be described as correct, be they spellings, maps, beliefs or intentions. But in fact, as Engel notes (ibid., 200), when something is correct it is always correct qua something or other. Being a correct spelling of a word - correct qua spelling of that word - is not the same property as being a correct belief correct qua belief. While both of these may be instances of the more general property of correctness qua $K$ (and hence, again, must not be confused with the corresponding standards of correctness, namely conforming to a certain orthographic convention, and having a true propositional content, respectively), it may be that one of them is normative and the other isn't. The nature of the kind $K$ may make a difference to whether correctness qua $K$ is normative. And, as noted in sec. 1 above, the sense in which false beliefs are wrong or incorrect does seem to be a sense that the believer must care about. So it remains plausible that some kind of normative property is involved here.

An objector may persist: this shows at most that doxastic correctness has normative significance, in the same way that bringing about pleasure, according to the utilitarian, has normative significance. That is, whenever it is instantiated, so too is some normative property. It does not show that doxastic correctness is itself a normative property.

While I think this objection has some force, we should not overestimate it. For one thing, the impression remains that labelling a belief incorrect has the flavour of a normative claim, in a way that noting that an action fails to maximise pleasure does not. Secondly, the view suggested by the objection raises the question why we bother talking about correctness at all. Why not just say that, when beliefs are true, this gives them whatever further normative property it is they are claimed to have? Correctness seems like an idle middleman, on this view. I take it that those, like Engel, who think of doxastic correctness as normative, do not think of it as merely playing this middleman role between truth and whatever property is doing the real normative work. They think of it as something normative in its own right. 
So I will continue to assume that doxastic correctness is itself normative - though many of the considerations below are also relevant to the weaker view according to which doxastic correctness is merely normatively significant, in the sense indicated above.

If doxastic correctness is indeed normative, we can ask: what kind of normative property is it? I now turn to this question. While Engel's answer to this question does not depend, I think, on his claims about $e$ - and $i$-correctness, I will suggest a view that requires us to construe doxastic correctness as a kind of $e$-correctness.

\section{Correctness, Ideals of Reason, and Fittingness}

Among those who hold that doxastic correctness is normative, the most common view is that this norm is deontic or prescriptive in character (e.g. Shah 2003, Whiting 2013). That is, it says that we ought not believe what's false, and that we ought (or may) believe what's true. Here, 'ought' and 'may' are understood in their normal senses, as prescribing, permitting or forbidding certain pieces of conduct, and as suitable for guiding this conduct. In this case they would apply to our doxastic conduct.

There are well known objections to this sort of view. Some turn on guidance. To follow a prescription to believe the truth, it seems, you would have to first identify those propositions that are true, and then go on to believe them. But to identify a proposition as true entails believing it. Thus, you would never be able to follow the prescription without already forming a belief, rendering the prescription idle. ${ }^{7}$

Other objections turn on whether prescriptive normative notions map well onto the normative statuses of different doxastic attitudes. Any true belief is correct, but it's not the case that, for each true thing, you ought to believe it. So correct belief does not seem to be the same thing as belief that you ought to have: correctness is not obligatoriness. If correctness is nonetheless a prescriptive property, then the remaining candidate seems to be permissibility. But correctness seems to be a positive normative standing in a way that mere permissibility isn't. It is often permissible to suspend judgment on a question, but it is never correct in the same way as true belief: when you suspend judgment you are

\footnotetext{
${ }^{7}$ Glüer and Wikforss (2009). See Engel (2013a, 2013b), Steglich-Petersen (2013) and Wedgwood (2013) for discussion.
} 
not getting things right in the way that you are when you believe the truth. So it is not clear what prescriptive or deontic status true belief might plausibly have. ${ }^{8}$

Engel agrees that doxastic correctness is not prescriptive, and proposes an alternative view. The truth norm, he writes

"does not give us any prescriptive_or even permissive_-guidance... It is an ideal of reason, in the sense that it tells you what you ought to ideally believe, namely the truth, and thus it belongs to the category of the ought-to-be rather than to the category of the ought-to-do" (loc. cit., 208).

This is an intriguing suggestion for retaining a normative view of doxastic correctness, without getting into the difficulties associated with the prescriptive version of this view.

One might worry about Engel's seeming abandonment of the idea that the truth norm guides believers. When we reason theoretically, for example, we certainly seem to be guided by truth in some way; modulo self-deception and other such funny business, we typically form through reasoning only beliefs that we take our evidence to support. This fact requires explanation. It would be surprising if the explanation had nothing to do with the fact that true belief is correct belief, and that believers are in some way sensitive to this. Indeed, facts about the kinds of considerations to which believers are sensitive in their theoretical reasoning are, for some theorists, the primary motivation for positing a normative standard of correctness for belief in the first place (Shah 2003).

However, we can read Engel here not as denying that the truth norm plays any role in guiding our doxastic endeavours, but rather as denying that it does so in the manner of a prescription (cf. Engel, loc. cit., 212). We can, after all, be guided by ideals, without thinking of failure to satisfy them as forbidden.

\footnotetext{
${ }^{8}$ See also Bykvist and Hattiangadi (2007), McHugh (2012), Svavarsdóttir (2014). For replies see Whiting (2013).
} 
Nonetheless, I don't find the proposal fully satisfying. I will set out a few initial worries about it, before raising some questions about how it relates to other views that take doxastic correctness to be normative in a broad sense, even if not deontic or prescriptive.

If believing the truth is an ideal of reason, then failing to do so would presumably constitute a failure, or at least a falling-short, of reason. But false beliefs do not seem always to constitute such a failure or falling-short. In a situation of misleading evidence, believing what is in fact false might be perfectly reasonable and rational. It seems that, far from true belief being an ideal of reason, what reason (or perhaps Reason with a capital R) tells you to do is to believe according to your evidence. Of course, Reason does this precisely because true belief is correct, but nonetheless the failure to attain true belief need not be a failure of Reason.

Perhaps the idea is that true belief is an ideal of reason not in the sense that failure to believe truly is less than fully reasonable, but rather in the sense that the standards for what is reasonable somehow 'aim' at truth. For example, perhaps the point of satisfying these standards is to get true beliefs. I think there is something right about this, but I am unsure about the suggestion that believing the truth is an ideal, if this means merely an ideal. The term 'ideal' has a whiff of the supererogatory. Ideals seem to be things that we should aspire to, but failure to satisfy which need not involve going wrong and is not normally grounds for serious criticism or blame. While falsity in a belief can be blameless and beyond criticism, it nonetheless involves going wrong and seems like the sort of thing we should be worried about, and rectify when we become aware of it. To believe wrongly is not merely to manifest one's inevitable human fallibility and imperfection. It seems a more urgent matter than that.

Ideals also seem typically to be things that we can be more or less close to satisfying, and guidance by which involves endeavouring to get closer to satisfying. While omniscience is like that, doxastic correctness as such doesn't seem to be. Doxastic correctness is a property of particular beliefs, not of belief systems, and they either have it or they don't. ${ }^{9}$

For these reasons, I'm not sure that I have a grip on how doxastic correctness could be fundamentally either an ideal or a standard of reason.

\footnotetext{
${ }^{9}$ Engel rejects Wedgwood's claim that doxastic correctness comes in degrees (Wedgwood 2013). I agree with Engel on this point.
} 
This is not to say that we should return to the idea that the truth norm guides by prescribing true beliefs, and forbidding false ones. Our notion of guidance, and of normativity, need not be so narrow. Indeed, I think that Engel's work has done a great deal to illuminate this point, and to show that the options available to those who hold that doxastic correctness is normative are not as restricted as some of their critics suppose. In closing, I want to turn briefly to some of these other options.

The normative, in the broad sense in which it is opposed to the descriptive, includes evaluative properties as well as deontic ones. To say that something is good, or that it is good of its kind, is a normative claim in this broad sense. One might claim, then, that doxastic correctness is an evaluative property.

Indeed, one might read Engel's proposal as a version of this kind of view. Ideals seem to be standards for evaluation. Failure to satisfy an ideal is not necessarily a big problem, but the closer one gets to satisfying it, the better. Engel also talks of 'ought-to-be'. This looks like an evaluative notion. For example, the claim that the world ought to contain less suffering seems to be an evaluative claim, to the effect that it would be better if the world contained less suffering.

Notwithstanding my concerns about thinking of true belief as a mere ideal, I think that the evaluative view of doxastic correctness is attractive. Some goods are more than mere ideals.

Some philosophers have expressed doubt or puzzlement about the claim that true belief is good simpliciter (e.g. Heal 1988; David 2005). But the value of true beliefs can be understood as a form of attributive value--we can say, roughly, that the belief that $p$, when true, is good qua belief about whether $p .{ }^{10}$ Believers may plausibly be guided by such a value. For example, the value of true belief may make it the case that evidence for a proposition constitutes a reason to believe that proposition-which reason can then guide thinkers in their theoretical reasoning. It is not controversial that evidence can guide our believing in the sense of giving reasons that we respond to by believing this or that. At the same time, this value would not generate implausibly strong or impossible-to-follow prescriptions. Just because the belief that the plant on my desk has 41 leaves is good qua belief about whether it does, it doesn't follow that you ought to have this belief. It may be that you are permitted to have no belief at all concerning this matter.

\footnotetext{
${ }^{10}$ I tentatively defended such a view in McHugh (2012).
} 
Nonetheless, the evaluative view faces some objections. For one thing, it is not clear that attributive goodness is connected to reasons in the way that would be required in order for this view to explain the special role of evidence in giving reasons for and against belief. Suppose you are choosing a car. Indications that a particular car is a good one might give you reasons for choosing it. But other reasons, that have nothing to do with whether it is a good car, but that are relevant to other goods, might count against it (or for it). For example, it might be very expensive, or not fit in your driveway. Indeed, in certain circumstances you might reasonably be entirely indifferent to whether the car you choose is a good car, and there need be nothing criticisable or irrational about picking the bad one. You might want it for scrap metal. In general, then, the standard for being a good $F$ does not determine in a straightforward way the reasons that bear on our dealings with $F$ s.

By contrast, the standard of truth does seem to determine, to a great extent, the reasons that bear on our dealings with beliefs. It's always criticisable or irrational, in an important sense, to believe contrary to your evidence, even if so believing would be good in some way. We should expect the nature of doxastic correctness to help explain this. The idea that doxastic correctness is a form of attributive value does not seem to do so.

However, to my mind, the most compelling objection to the evaluative view is the simple thought that correctness and attributive goodness are just very different sorts of properties. Correctness seems to be a matter of there being a certain sort of fit or match between two things. Attributive goodness is different. For something to be a good knife, or a good heart, is not for it to fit some other thing, but rather for it to have properties that enable it to perform its function appropriately in normal conditions. We are not at all tempted to say that good knives and good hearts are thereby correct knives or correct hearts. This suggests that attributive goodness and correctness are different properties. ${ }^{11}$

\footnotetext{
${ }^{11}$ Perhaps the point is less clear when we consider objects of evaluation whose function is to fit or match something - as might be argued to be the case for belief. For example, perhaps a correct solution to a puzzle is simply a good solution - it's a solution that does well what solutions are supposed to do, namely fit the criteria set down by the puzzle. I don't think that's quite right, though. It seems to me that a good solution is one that is efficient, clever, creative, or the like. That seems different from being a correct solution. What's more, the goodness of a solution to a puzzle comes in degrees, but its correctness does not. So I think that, even for kinds whose function is closely tied to a standard of correctness, being good of that kind is not the same as satisfying the standard of correctness. Thanks to an anonymous referee for pressing me here. For further objections to the evaluative view see McHugh (2014).
} 
Of course, this is compatible with the idea that being correct merely makes a belief good qua belief, rather than being itself an evaluative property. But, as noted at the end of the previous section, this is not the sort of view that I am trying to explore. Nor, as I understand it, is it the sort of view that Engel means to endorse (although I am open to correction here).

If doxastic correctness is neither a deontic property nor an evaluative one, does it follow that it is not normative at all? Not necessarily. It may be an instance of a normative property in its own right, neither deontic nor evaluative. This sort of view, which Thomson endorses, becomes plausible when we reflect on the connection between doxastic correctness and correctness for other, non-doxastic attitudes. As we saw earlier, intending a certain course of action can be correct or incorrect. Similarly, attitudes like admiring a person, desiring ice-cream, and fearing torture can all be correct or incorrect-or, as we might say, fitting or unfitting. This point is familiar from fitting-attitudes accounts of value, to which Engel makes reference (ibid., 203). As he says: "Correctness is determined by the way our attitudes fit a certain feature." When your attitude is fitting, whether it is an attitude of belief, intention, admiration, desire, or fear, you are getting things right in your orientation towards the world.

Note that this corresponds to $e$-correctness rather than $i$-correctness. The fittingness of an attitude depends on the features of its object. If you believe that whales are mammals and you intend to phone your sister on her birthday, your attitudes are fitting even if held on inadequate bases.

Correctness in this sense--fittingness--is a feature that certain attitudes have in virtue of the kinds of attitude they are. The agent cannot sensibly fail to care about it. You cannot sensibly keep admiring someone when you learn of all the overwhelming respects in which they are not admirable. While a performance of a tune, a map of a territory or a spelling of a word can be correct in the sense of satisfying certain conventional criteria, this does not make them fitting in this normative sense. You can sensibly be indifferent to the criteria in a given case.

Some proponents of fitting-attitudes accounts of value understand fittingness in terms of reasons: for an attitude to be fitting is for there to be sufficient reasons for it. But it's not at all obvious that fittingness should be understood in this way. Particularly so in the case of belief: what is fitting-correct--to believe is what is true, and, if justified false belief is possible, then what one has sufficient 
reasons to believe is not always what is true. My point here is that it is also far from obvious that fittingness must be understood in either deontic or evaluative terms. The domain of the normative may, as Thomson argues, be richer and more differentiated than philosophers have traditionally realised.

To what extent is the sort of view I am suggesting here a rival to Engel's? I am not sure. But I do want to insist that it is distinct from the evaluative view that some of his remarks may lead us towards. While fittingness need not be understood in terms of reasons, it may nonetheless be the case that, in so far as fittingness guides, it does so through reasons. When we engage in theoretical reasoning, what we think about, and what determines our conclusions, is reasons for believing this or that. How could this count as being guided by fittingness? Just as the evaluativist may claim that reasons are generated by values, so the defender of the fittingness view can hold that there is a systematic or constitutive connection between reasons and fittingness.

To see how this might work, consider the standard for good theoretical reasoning. Certain patterns of theoretical reasoning, such as the modus ponens pattern, are good patterns; others, such as the pattern of affirming the consequent, are bad. What makes the difference? It seems that the good patterns, but not the bad ones, are truth-preserving: they are such that, if you put true beliefs in and conform to the pattern, you will get a true belief out, other things equal.

By preserving truth, these patterns preserve correctness, or fittingness. This is surely not a coincidence. Truth-preserving patterns of theoretical reasoning are good, I suggest, because they preserve fittingness.

Now, if we assume that there is a close connection between reasons and good reasoning (Way forthcoming), we can begin to see why evidence has a special role in giving reasons for and against belief. If $p$ is good evidence for $q$, then, other things equal, the transition from believing $p$ to believing $q$ will preserve truth, and hence fittingness. By contrast, the transition from believing that it would be pleasant to believe $q$ to believing $q$ will not do so. So it is good reasoning to move from good evidence for $q$ to believing $q$, but not good reasoning to move from the pleasantness of believing $q$ to believing $q$. That is why evidence, but not pleasantness, gives reasons for belief. The fittingness view 
thus seems to be better positioned than the evaluative view to explain the special place of evidence in giving reasons for and against belief. ${ }^{12}$

Whether the sort of view sketched here is sustainable or not, I look forward to learning from Pascal Engel's further contributions to this debate.

\section{Acknowledgements}

Thanks to the editors of this special issue for putting it together and to a number of anonymous referees for very helpful comments. This work was supported by the Arts and Humanities Research Council [grant number AH/K008188/1].

\section{References}

Alston, W.P. (2005). Beyond Justification: Dimensions of Epistemic Evaluation. Ithaca, NY:

Cornell University Press.

Bonjour, L. (1985). The Structure of Empirical Knowledge. Cambridge, Mass.: Harvard UP.

Bykvist, K., and Hattiangadi, A. (2007). Does Thought Imply Ought? Analysis 67, 277-85.

David, M. (2005). On 'Truth is Good. Philosophical Books 46, 292-301.

Engel, P. (2004). Truth and the Aim of Belief. In D. Gillies (ed.), Laws and Models in Science. London: Kings College.

Engel, P. (2013a). In Defence of Normativism About the Aim of Belief. In T. Chan (ed.), The Aim of Belief. Oxford: OUP.

Engel, P. (2013b). Doxastic Correctness. Proceedings of the Aristotelian Society Supplementary Volume 87, 199-216.

Glüer, K., and Wikforss, Å. (2009). Against Content Normativity. Mind 118, 31-70.

Hattiangadi, A. (2007). Oughts and Thoughts: Rule-Following and the Normativity of Content. Oxford: OUP.

Heal, J. (1988). The Disinterested Search for Truth. Proceedings of the Aristotelian Society 88, 97108.

\footnotetext{
${ }^{12}$ For further details on the points of the last few paragraphs, see McHugh (2014).
} 
McHugh, C. (2012). The Truth Norm of Belief. Pacific Philosophical Quarterly 93, 8-30.

McHugh, C. (2014). Fitting Belief. Proceedings of the Aristotelian Society 114, 167-87.

Papineau, D. (2013). There Are No Norms of Belief. In T. Chan (ed.), The Aim of Belief. Oxford: OUP.

Parfit, D. (2011). On What Matters, Volume One. Oxford: OUP.

Rosen, G. (2001). Brandom on Modality, Intentionality and Normativity. Philosophy and Phenomenological Research 63, 611-23.

Shah, N. (2003). How Truth Governs Belief. Philosophical Review 112, 447-82.

Smithies, D. (2012). The Normative Role of Knowledge. Noûs 46, 265-88.

Sosa, E. (2007). A Virtue Epistemology: Apt Belief and Reflective Knowledge, Volume I. Oxford:

OUP.

Steglich-Petersen, A. (2013). The No Guidance Argument. Theoria 79, 279-83.

Svavarsdóttir, S. (2014). Having Value and Being Worth Valuing. Journal of Philosophy 111, 84-109.

Thomson, J. J. (2008). Normativity. La Salle, IL: Open Court.

Way, J. (forthcoming). Reasons as Premises of Good Reasoning. Pacific Philosophical Quarterly.

Wedgwood, R. (2002). The Aim of Belief. Philosophical Perspectives 16, 267-97.

Wedgwood, R. (2013). Doxastic Correctness. Proceedings of the Aristotelian Society Supplementary Volume 87, 217-34.

Whiting, D. (2013). Truth: the Aim and Norm of Belief. Teorema 32 (3), 121-35. 